\title{
ИНДИВИДУАЛЬНЫЕ ОСОБЕННОСТИ СТРЕССОРНОГО РЕАГИРОВАНИЯ ВО ВРЕМЯ ПСИХОФИЗИОЛОГИЧЕСКОГО ИССЛЕДОВАНИЯ С ПРИМЕНЕНИЕМ ПОЛИГРАФА
}

\author{
Ермаков Павел Николаевич \\ Воробьева Елена Викторовна \\ Яцык Геннадий Геннадьевич
}

Работа выполнена в рамках проектной части внутреннего гранта Южного федерального университета № 213.01-07-2014/15ПЧВГ «Угрозы национальной безопасности в условиях геополитической конкуренции и модели агрессивного и враждебного поведения молодежи»

Работа посвящена изучению влияния индивидуально-типологических различий испытуемых на физиологические показатели реагирования во время процедуры тестирования на полиграфе.

В работе была проведена оценка: свойств нервной системы (силы, баланса и подвижности) с применением методики (ЗМР-3 - сложной зрительно-моторной реакции; характерологических индивидуальных различий с применением теста акцентуаций характера К. Леонгарда и Г. Шмишека; показателей вегетативных реакций испытуемых (электрической активности кожи, верхнего и нижнего дыхания, сердечно-сосудистой активности, а также тремора) с применением профессионального компьютерного полиграфа «ПОЛАРГ-М» со спечиальным программным обеспечением «Фемида». В исследовании с применением полиграфа применялись следующие методики: стимуляционно-адаптирующий тест (САT), тест общих контрольных вопросов (ТОКВ) и поисковый тест на знания виновного (П-ТЗВ). В работе приняли участие 30 человек в возрасте от 18 до 24 лет.

В результате исследования показано, что испытуемые с ярко выраженным свойством силы нервной системы способны более успешно противостоять процедуре тестирования на полиграфе. Выявлено влияние характерологического комплекса «тревожность - эмотивность» на амплитуду позитивной и негативной полуволн в канале электрической активности кожи. Показана принципиальная возможность дифференцирования реакций 
испытуемых, вызванных тревожностью либо значимостью стимула, что позволяет избежать ошибки ложного обвинения. Показано, что различные способы реагирования на стресс могут формировать индивидуальные формы физиологических реакций. В этих условиях ключевое значение приобретает понятие индивидуального симптомокомплекса как уникального набора параметров физиологических реакций, возникающих при предъявлении исследуемому личу субъективно значимых стимулов.

Ключевые слова: индивидуальные особенности, полиграф, стресс, эмотивность, тревожность, переключаемость, симптомокомплекс, сила НС, акцентуации характера, кожно-гальваническая реакция.

\section{Введение}

Вопросы государственной и общественной безопасности являются одними из самых важных направлений в деятельности любого государства. В этой связи учет человеческого фактора имеет особое значение. Именно поэтому исследования в области выявления скрываемой человеком информации являются одними из самых актуальных в современной психологической науке [14]. На сегодняшний день существует большое количество методов тестирования психики испытуемых с целью выявления скрываемой ими информации. В рамках психологической науки в этой области имеется большое количество концепций, начиная от чисто «психологических», таких как оперативная психодиагностика, анализ невербального поведения и других [3, 20], заканчивая методами, в основе которых лежит применение специальных устройств, регистрирующих изменение физиологической активности испытуемых [5].

Наиболее научно обоснованным и широко применяемым сегодня является метод детекции скрываемой информации с применением полиграфа. Опрос с применением полиграфа - это психофизиологическое исследование (ПфИ), в ходе которого проводится регистрация деятельности вегетативной нервной системы испытуемого во время предъявления ему опросников, содержащих релевантные и нерелевантные стимулы. Именно анализ и сравнение между собой реакций на эти стимулы и дает возможность судить о наличии или об отсутствии определенной информации у испытуемого. Один из наиболее авторитетных современных исследователей в области инструментальной «детекции лжи» Ю. И. Холодный характеризует процесс ПфИ с применением полиграфа как исследование памяти человека с целью обнаружения наличия (или отсутствия) следов событий, имеющих уголовно-релевантное значение [19].

Одной из самых актуальных проблем, по мнению многих отечественных и зарубежных исследователей в области полиграфологии, является вопрос о значении индивидуально-типологических различий испытуемых при 
проведении психофизиологического исследования с применением полиграфа $[1,2$, 4, 6, 7, 9, 10, 16, 18, 19, 21, 24].

Особое место в исследованиях в области детекции скрываемой информации занимает метод регистрации электроэнцефалограммы и вызванных потенциалов мозга. Как показано во многих исследованиях, волна Р300 является одним из наиболее достоверных маркеров процесса сокрытия информации $[12,22,23]$. Интересные результаты были получены в результате ЭЭГ-исследований индивидуальных различий. Так, было показано, что как особенности темперамента, так и уровень мотивации испытуемых при выполнении заданий довольно отчетливо отражаются в динамике ЭЭГ, а последняя, в свою очередь, непосредственно коррелирует с динамикой чСС $[25,26,27]$.

Как правило, процедура тестирования на полиграфе носит стрессогенный характер для исследуемого лица. Это может быть связано и с боязнью ложного обвинения, и просто с незнанием элементарных основ работы полиграфа. Так или иначе, но стресс - это один из самых важных факторов, который должен быть учтен при проведении тестирования на полиграфе.

Один из наиболее уважаемых современных ученых в области изучения стрессового поведения Д. А. Жуков дает следующее определение стресса: «Стресс - это неспецифическая системная приспособительная реакция организма на новизну, т. е. на отклонение условий существования от привычных» [8]. Исследователь подчеркивает, что степень стрессорности ситуации для конкретного человека зависит от его индивидуально-типологических особенностей. Для интроверта такой стрессорной ситуацией может оказаться простое общение с незнакомым человеком, а у экстраверта причиной стресса может стать простая, но монотонная работа [8].

Выделяют два типа поведения человека при возникновении стрессовой ситуации: реакция по типу «борьбы или бегства» и реакция по типу «затаивание». Указанные типы реагирования связаны с индивидуальными особенностями реагирования и возможными различиями реагирования на физиологическом уровне $[9,10]$.

Одну из самых важных проблем ПфИ с применением полиграфа затронули С. И. Оглоблин и А. Ю. Молчанов, указав на две разновидности ошибок, которые может совершить полиграфолог при проведении исследования:

а) ошибки І-го типа, которые трактуются как «ложная тревога», «обвинение невиновного» или «ошибочное принятие обвинительной версии»;

б) ошибки II-го типа, которые определяются как «пропуск цели», «оправдание виновного» или «ошибочное принятие оправдательной версии» [16].

Нам представляется, что расширение исследований в области индивидуально-типологических различий испытуемых при проведении тестирования 
на полиграфе будет способствовать более точному пониманию тех или иных физиологических реакций испытуемых, что позволит повысить точность и обоснованность проводимых исследований.

Целью нашего эмпирического исследования было изучение влияния индивидуально-типологических различий испытуемых на физиологические показатели реагирования во время процедуры тестирования на полиграфе.

Нами были выдвинуты следующие гипотезы:

1. Индивидуальные характерологические различия испытуемых могут оказывать значимое влияние на частоту и величину проявления тех или иных информативных признаков во время процедуры тестирования на полиграфе.

2. Индивидуальные особенности свойств нервной системы испытуемых могут оказывать влияние на физиологические показатели реагирования испытуемых, такие как амплитуда, латентность и скорость протекания реакций, что может сказываться на вероятности правильного определения значимых стимулов.

\section{Методика}

Проведенное нами эмпирическое исследование состояло из следующих этапов:

1) целью первого этапа исследования было получение данных об индивидуально-типологических различиях испытуемых;

2) на втором этапе испытуемые проходили тестирование на полиграфе;

3) полученные данные были обработаны при помощи методов математической статистики.

В эксперименте приняли участие 30 испытуемых, из них 16 мужчин и 14 женщин, в возрасте от 18 до 24 лет. Никто из испытуемых ранее не проходил процедуру тестирования на полиграфе.

Первым этапом данного экспериментального исследования было проведение комплекса тестов, целью которых было выявление индивидуальнотипологических различий испытуемых. Свойства нервной системы (сила, баланс, подвижность) выявлялись при помощи устройства психофизиологического тестирования УПФТ 1/30 - «ПСИХОФИЗИОЛОГ» с применением методики СЗМР-3 - сложной зрительно-моторной реакции с выбором из двух альтернатив в 3 этапа [17].

Для определения характерологических индивидуальных различий был использован тест-опросник для определения акцентуаций характера К. Леонгарда и Г. Шмишека. В результате применения теста-опросника каждому испытуемому было присвоено значение от 0 до 24 баллов по каждой из десяти акцентуаций, включенных в тест [13]. 
Bmopoŭ эman нашего эксперимента представлял собой процедуру психофизиологического исследования с применением полиграфа. Главной целью данного этапа исследования являлось получение характеристик индивидуального симптомокомплекса испытуемых. Здесь важно дать определение этого термина. Нам представляется наиболее точным определение, приведенное Р. С. Ивановым: «индивидуальный симптомокомплекс - это уникальный набор параметров физиологических реакций, возникающий при предъявлении исследуемому лицу субъективно значимых стимулов, обусловленный его оптимальным функциональным состоянием в ходе всего процесса психофизиологического исследования с применением полиграфа» [9].

Тестирование на полиграфе проводилось под общим руководством опытного эксперта полиграфолога, с соблюдением всех соответствующих процедуре требований и рекомендаций, принятых на сегодняшний день в Российской Федерации:

- с каждым испытуемым предварительно проводилась предтестовая беседа, в ходе которой испытуемому сообщались все необходимые сведения о предстоящей проверке и обсуждаемых в ходе этой проверки вопросах. В течение данного этапа исследователь также собирал информацию об испытуемом, которая учитывалась при последующем составлении и корректировании тестов;

- в исследовании применялись наиболее распространенные и апробированные на сегодняшний день тестовые методики: стимуляционно-адаптирующий тест (САТ), тест общих контрольных вопросов (ТОКВ) и поисковый тест на знания виновного (П-ТЗВ);

- каждый тест, использованный при проведении проверки на полиграфе, предъявлялся 4 раза;

- порядок предъявления всех вопросов в тестах изменялся от предъявления к предъявлению, чтобы избежать позиционного эффекта;

- на момент проведения тестирования в лаборатории находились только экспериментатор и испытуемый;

- в поле зрения испытуемого не попадали ни полиграф, ни исследователь;

- непосредственно перед каждым тестом с испытуемым обсуждались вопросы, которые планируется предъявлять во время этого теста.

Для регистрации вегетативных реакций использовался профессиональный компьютерный полиграф «ПОЛАРГ-М» со специальным программным обеспечением «Фемида». Для регистрации физиологической активности испытуемых использовались три основных канала и один дополнительный: канал электрической активности кожи, верхнего и нижнего дыхания, сердечно-сосудистой активности, а также канал регистрации тремора. 


\section{Результаты исследования}

В результате эмпирического исследования были получены данные об индивидуально-типологических различиях испытуемых и особенностях проявления их индивидуального симптомокомплекса. По каждому испытуемому в сумме было собрано 29 переменных, измеренных как в номинативной шкале, так и в шкале абсолютных величин. В качестве статистического теста в нашем исследовании был использован метод непараметрической корреляции Спирмена. Также был использован факторный анализ, целью которого было выявление возможных скрытых переменных, влияющих на формирование симптомокомплекса. Для оценки возможностей прогнозирования особенностей симптомокомплекса нами был использован метод множественного регрессионного анализа [15].

В результате проведения корреляционного анализа нами была получена высокая отрицательная корреляционная связь между свойством силы нервной системы и успешностью определения программой «Фемида» реализации ложных ответов ( $\left.r s=-0,496^{* *}, p<0,01\right)$. Интересная корреляционная связь была выявлена между переменными свойствами переключаемости нервных процессов и амплитудой негативной полуволны в канале КГР (rs =0,392*, p < 0,05), что также может косвенно свидетельствовать о валидности данных, полученных в ходе исследования, т. к. негативная полуволна по каналу КГР - это показатель, отражающий, в том числе, работу свойства переключаемости нервных процессов.

Особое внимание стоит уделить корреляционным связям между позитивной и негативной полуволнами (канал КГР) с тревожностью и эмотивностью. Уровень значимости этих связей составляет $p<0,05$. Их корреляционная связь устойчиво проявлялась на всех промежуточных этапах обсчета эмпирических данных и при использовании различных методов математической статистики. Интересной эта связь представляется из-за выявленной закономерности: позитивная полуволна имеет устойчивую корреляционную связь и с тревожностью ( $\left.r s=0,379^{*}, p<0,05\right)$, и с эмотивностью ( $r s=0,434^{*}, p<0,05$ ), в то время как негативная полуволна имеет устойчивую связь только с эмотивностью ( $\left.r s=0,404^{*}, p<0,05\right)$.

Полученные нами данные были обработаны при помощи факторного анализа. Результаты представлены в таблице 1.

В результате факторного анализа удалось классифицировать данные. Первый фактор (переключаемость нервных процессов, тревожность, позитивная и негативная полуволны) можно охарактеризовать как группу, влияющую на амплитуду реагирования по каналу КГР, второй фактор (демонстративность, гипертимность, реакция облегчения) - группа корреляций, влияющих на реакцию облегчения, а третий (сила нервной системы, эмотивность, 
эффективность работы программы «Фемида») - фактор успешности определения программой «Фемида» реализации ложных ответов.

Таблица 1.

Матрица перевернутых компонент исследуемых переменных

\begin{tabular}{|c|c|c|c|c|}
\hline & \multicolumn{4}{|c|}{ Компонента } \\
\hline & $\mathbf{1}$ & $\mathbf{2}$ & $\mathbf{3}$ & $\mathbf{4}$ \\
\hline Сила НС &, 054 &, 076 &, 823 &,- 154 \\
\hline $\begin{array}{c}\text { Переключаемость } \\
\text { НС }\end{array}$ &, 700 &,- 202 &,- 007 &,- 399 \\
\hline Демонстративность &, 050 &, 910 &,- 162 &,- 022 \\
\hline Педантичность &, 039 &,- 125 &,- 064 &, 908 \\
\hline Гипертимность &,- 191 &, 812 &, 153 &,- 069 \\
\hline Тревожность &, 643 &, 264 &, 165 &, 217 \\
\hline Эмотивность &, 360 &,- 114 &, 606 &, 180 \\
\hline Облегчение &, 386 &,- 547 &,- 079 &, 430 \\
\hline Позитивная п-на &, 758 &,- 125 &, 340 &, 158 \\
\hline Негативная п-на &, 749 &,- 316 &, 192 &, 018 \\
\hline «Фемида» &,- 163 &,- 024 &,- 820 &, 044 \\
\hline
\end{tabular}

Последним методом математической статистики, примененным в нашем исследовании, стал метод множественного регрессионного анализа (МРA). Первой регрессионному анализу мы подвергли самую значимую корреляцию нашего исследования - свойство силы нервной системы и успешность определения программой «Фемида» значимых стимулов. Анализ показал, что коэффициент детерминации этой регрессии нельзя назвать высоким (R-квадрат $=0,278)$, в то время как высокая отрицательная значимость связи была подтверждена (коэффициент $ß=-0,528$ ). Графическая модель регрессии отображена в рисунке 1 .

Ожидаемыми оказались результаты анализа комплекса «эмотивность тревожность» и амплитуды позитивной полуволны. Коэффициент детерминации (R-квадрат) был равен 0,250, а важность переменных (коэффициент ß) составила 0,344 для эмотивности и 0,274 для тревожности, что примерно сопоставимо. Графическое изображение этих регрессий можно увидеть на рисунках 2 и 3. 


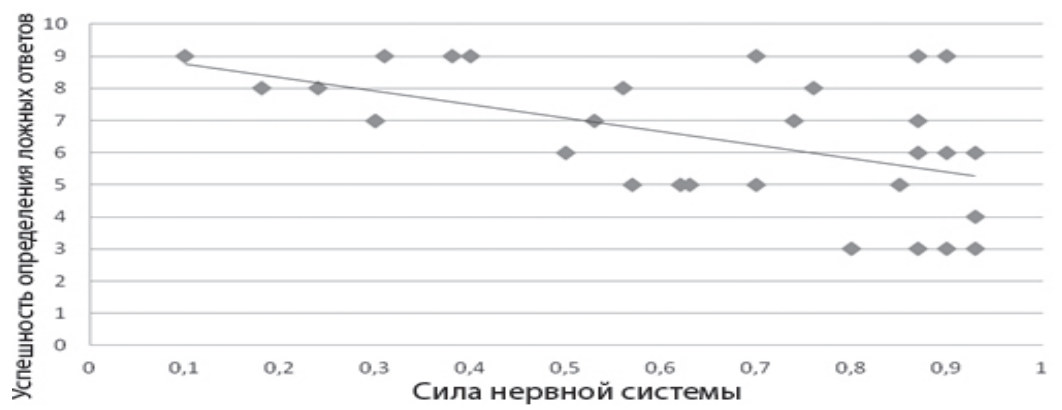

Рисунок 1. Зависимость силы нервной системы и успешности определения ложных ответов программой «Фемида»

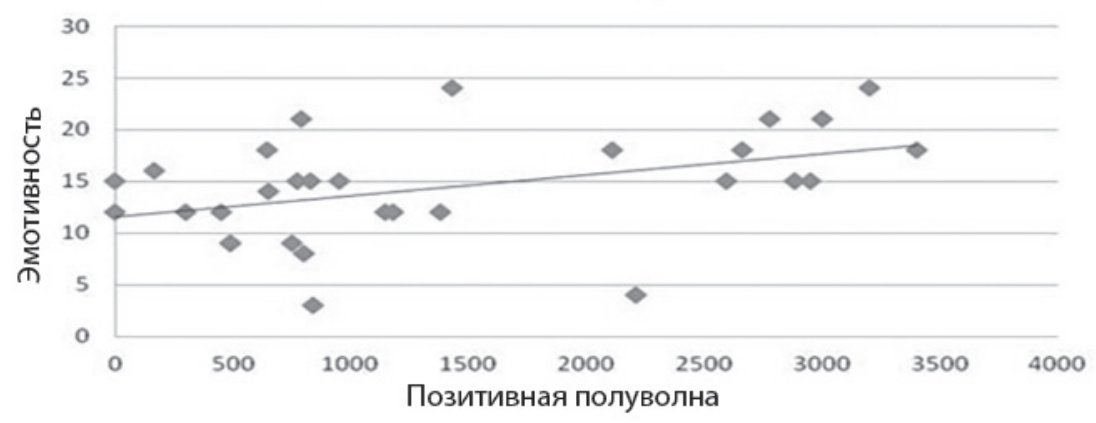

Рисунок 2. Регрессия позитивной полуволны и эмотивности

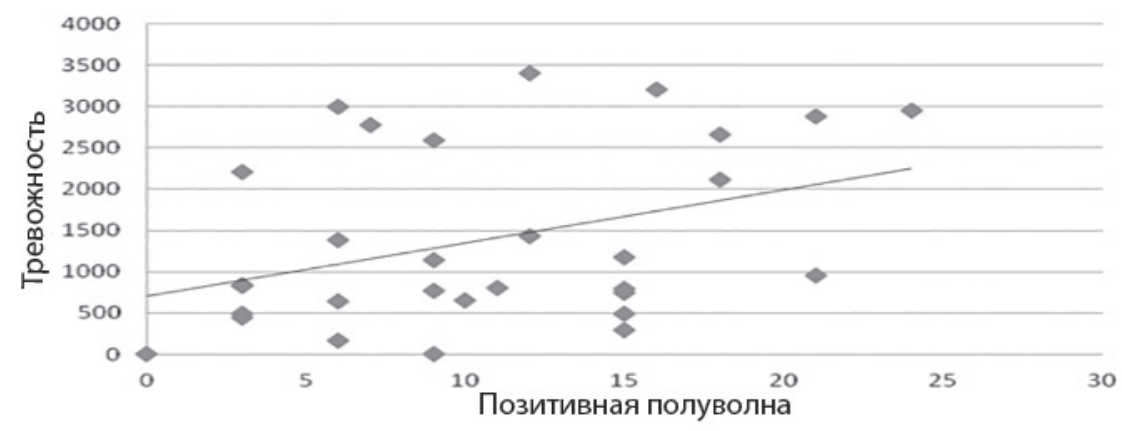

Рисунок 3. Регрессия позитивной полуволны и тревожности 
Наибольший интерес вызвал анализ результатов корреляций эмотивности, тревожности и переключаемости нервных процессов с позитивной и негативной полуволнами. По результатам анализа регрессии группы «тревожность, эмотивность и свойство переключаемости» (независимые переменные) с амплитудой негативной полуволны (зависимая переменная), автоматический обсчет исключил корреляцию тревожности из расчетов, посчитав ее незначимой. При этом коэффициент детерминации регрессии одного параметра «эмотивность» составлял 0,178 (R-квадрат), а в сумме с переключаемостью нервных процессов уже составил 0,295 (R-квадрат), причем важность переменных (коэффициент ß) для «эмотивности» составлял 0,362, а для «переключаемости НП» 0,347, т. е. они были равнозначны. На рисунке 4 изображена регрессия негативной полуволны и эмотивности.

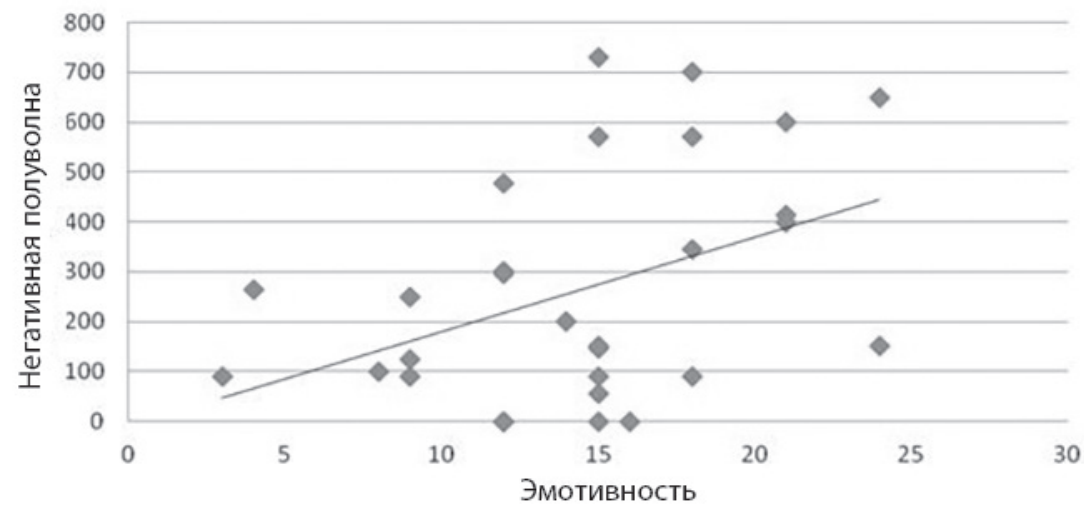

Рисунок 4. Регрессия негативной полуволны и эмотивности

\section{Обсуждение результатов}

Подводя итоги нашего эмпирического исследования, можно заключить, что поставленная цель была реализована, а гипотезы подтвердились. Мы выяснили, что индивидуально-типологические особенности оказывают значимое влияние на формирование индивидуального симптомокомплекса и что учет психологических и психофизиологических характеристик человека в равной степени важен.

В результате нашего исследования было выявлено, что среди психофизиологических особенностей испытуемых наибольшее влияние на формирование симптомокомплекса физиологического реагирования оказывают свойство силы нервной системы и свойство переключаемости нервных процессов. 
Среди психологических характеристик наиболее значимыми для формирования симптомокомплекса испытуемых оказались такие характеристики, как демонстративность, педантичность, гипертимность, тревожность и эмотивность. В качестве зависимых переменных выступили амплитуда позитивной и негативной полуволн (канал КГР), реакция облегчения (канал ПГ), а также эффективность определения программой «Фемида» реализации ложных ответов. Следует сказать, что полученные нами данные, в целом, можно разделить на две группы: данные, которые с определенной степенью осторожности могут быть учтены при проведении специалистом действительной проверки на полиграфе, и данные, которые представляют собой только научный интерес и требуют дальнейших исследований.

Наиболее значимая отрицательная корреляция была выявлена между свойством силы нервной системы и успешностью определения программой реализации ложного ответа испытуемым ( $<<0,01)$. Эта связь представляется нам логически понятной и объяснимой. Об этом говорит и Л. Г. Алексеев, обращая внимание на то, что сила нервной системы имеет большое значение в условиях стрессовых ситуаций [1]. Е. П. Ильин приводит данные о том, что у лиц со слабой нервной системой быстрее происходит снижение эффективности реагирования [11]. Приведенных данных из литературы достаточно, чтобы заключить, что существование этой корреляции связано с тем, что лица с сильной нервной системой способны дольше выдерживать стрессовые нагрузки и дольше находиться в «эффективном» состоянии, даже в моменты реализации ложных ответов. Но, помимо описанной корреляции, по результатам факторного анализа были получены данные о том, что в одну группу с вышеуказанными переменными была включена также и такая переменная, как эмотивность. Это может быть связано с тем, что эмотивность имела наибольшие корреляции как с позитивной, так и с негативной полуволнами (канал КГР). Вполне возможно, что это связано с тем, что канал КГР в лабораторных исследованиях наиболее наглядно демонстрирует значимость стимулов.

Пожалуй, самым значимым результатом нашего эмпирического исследования стала выявленная связь комплекса «эмотивность - тревожность» с позитивной и негативной полуволнами.

Корреляционный анализ показал, что позитивная полуволна имеет значимые корреляции с переменными «тревожность» и «эмотивность» $(p<0,05)$, в то время как негативная полуволна имеет значимые корреляции лишь с эмотивностью ( $<<0,05)$, а с тревожностью таковых обнаружено не было. Это позволило нам сделать предварительные выводы о том, что высокоамплитудная позитивная полуволна в сочетании с амплитудной негативной полуволной может служить индикатором того, что человек эмоционально воспринимает отдельные из предъявленных ему стимулов, или же, в случае 
отсутствия амплитудной негативной полуволны, испытывает тревогу по поводу задаваемых ему вопросов.

Применение дополнительных методов математической статистики, таких как факторный анализ и множественный регрессионный анализ, подтвердило полученные нами данные. Также удалось выявить, что помимо эмотивности на величину негативной полуволны оказывает влияние также и свойство переключаемости нервных процессов.

\section{Выводы}

В результате исследования были получены данные о значительной отрицательной $(p<0,01)$ связи свойства силы нервной системы с успешностью определения программой «Фемида» релевантных стимулов. Эти данные подтверждают предположения Л. Г. Алексеева об отрицательной корреляции развитой эмоционально-волевой сферы и успешности определения релевантных стимулов [1].

Установлена корреляционная связь амплитуды позитивной полуволны в канале электрической активности кожи с тревожностью и эмотивностью $(p<0,05)$, а также связь амплитуды негативной полуволны с эмотивностью $(p<0,05)$. Это позволяет нам утверждать о принципиальной возможности использования комплекса «тревожность - эмотивность» для более точной диагностики вызываемых у испытуемых эмоций во время предъявления им вопросников, а также для снижения риска допущения ошибки ложного обвинения.

Теоретический анализ современной литературы и результаты проведенной нами эмпирической работы позволяют сказать, что исследования в области влияния индивидуально-типологических различий испытуемых на особенности их физиологического реагирования имеют большой научный и практический интерес. Не вызывает сомнения необходимость теоретического обоснования и практического подтверждения выявленной нами связи комплекса «тревожность - эмотивность» с позитивной и негативной полуволнами в канале электрической активности кожи. В этой связи нам представляются наиболее перспективными исследования в области стрессорных и гормональных механизмов человека и их влияния на индивидуальный симптомокомплекс испытуемых.

\section{Литература}

1. Алексеев Л. Г. Психофизиология «детекции лжи». - М., 2011.- С. 30, 41, 105.

2. Варламов В. А., Варламов Г. В. Компьютерная детекция лжи. - Краснодар: Илигар, 2010. - 946 с.

3. Гоннов Р. В., Ляшенко В. Н. Бесконтактная детекция лжи как важный инструмент сотрудника полиции // Научно-методические проблемы 
подготовки инструкторско-педагогических кадров по боевой и физической подготовке для органов внутренних дел // Сборник материалов VIII межвузовской научно-практической конференции. - Ставрополь, 2015. - С. 7-12.

4. Дикий И.С. Влияние психофизиологических и психологических особенностей участников полиграфных проверок на характер проявления информативных признаков / Центр специальных исследований и экспертиз // URL: http://www.psy-expert.ru/publ/16-1-0-47

5. Дикий И. С. Возможности применения полиграфа и новых альтернативных методов инструментальной детекции лжи для предупреждения террористических угроз // Российский психологический журнал. 2010. - Т. 7. - № 5-6. - С. 63-67.

6. Дикий И. С. Психофизиологические особенности субъектов в условиях инструментальной детекции скрываемой информации: дисс. ... канд. психол. наук. - Ростов н/Д, 2011. - 173 с.

7. Ермаков П. Н., Иванов Р. С. Организационно-методические аспекты судебно-психофизиологической экспертизы с применением полиграфа // Методическое пособие для студентов психологических и юридических вузов. - М., 2015.

8. Жуков Д. А. Стой, кто ведет? Биология поведения человека и других зверей: в 2 т. - Т. 1. - М., 2015. - С. 428.

9. Иванов Р. С. Индивидуальный симптомокомплекс как инструмент интерпретации результатов психофизиологического исследования с применением полиграфа // Национальный психологический журнал. 2014. - № 3 (15). - С. 90-97.

10. Иванов Р. С. Пригодность психофизиологического состояния человека к применению полиграфа // Северо-Кавказский психологический вестник. - 2012. - № 10/1. - С. 9-12.

11. Ильин Е. П. Дифференциальная психофизиология. - СПб.: Питер, 2001. 463 c.

12. Кузнецов Д. А., Воробьева Е. В. К вопросу об использовании метода анализа электрической активности мозга в сфере детекции лжи // Личность в современном обществе: социализация, поведение, общение: Материалы Всероссийской научной конференции (19-20 апр. 2007 г.) / Науч. ред. Н. И. Виноградова. - Чита, 2007. - С. 155-158.

13. Миронова Е. Е. Сборник психологических тестов. Часть I: Пособие. Минск: Изд-во Женского института ЭНВИЛА, 2005. - 155 с.

14. Мочагин П. В., Сметанин А. М. Детекция лжи: психофизиологическое исследование и основы информационной технологии выявления скрываемой информации // Вестник ИЖГТУ им. М. Т. Калашникова. - 2013. - С. 121. 
15. Наследов А. Д. Математические методы в психологии. - СПб.: Речь, 2012. - 392 c.

16. Оглоблин С. И., Молчанов А. Ю. Инструментальная «детекция лжи». Ярославль: Нюанс, 2004. - 464 с.

17. Руководство пользователя УПФТ-1/30 «Психофизиолог» / Научно-производственно-конструкторская фирма «Медиком МТД». - Таганрог, 2005.

18. Сошников А. П., Федоренко В. Н., Молчанов А. Ю. и др. Методика по проведению психофизиологических исследований с использованием полиграфа в кадровой работе, оперативно-розыскной деятельности и уголовном производстве. - М., 2008. - 90 с.

19. Холодный Ю. И. Опрос с использованием полиграфа и его естественнонаучные основы // Вестник криминалистики. - 2005. - № 1 (13). - С. 39-48.

20. Черкасова Е. С. Профайлинг как метод создания психологического портрета потенциального преступника на этапе организации предварительного расследования // Вестник Новосибирского государственного университета. - 2013. - С. 72-73.

21. Barland G. H., Raskin D. C. Detection of Deception. In Electrodermal Activity in Psychological Research. - N. Y.: Academic Press, 1973.

22. Dikiy I. S., Dikaya L. A., Ermakov P. N. Amplitude and latency of components of event related potentials as indicators of false responses in participants with different modes of thinking // International journal of psychophysiology. 2012. - V. 85. - Issue 3. - P. 378. doi:10.1016/j.jpsycho.2012.07.041

23. Dikiy I. S., Ermakov P. N. Interhemispheric distribution of components of Event-related potentials during false responses // International Journal of Psychology. - 2012. - V. 47. - Supp. 1. Special Issue: XXX International Congress of Psychology. - pp. 145-146.

24. Gronau N., Ben-Shakhar G., and Cohen A. Behavioral and Physiological Measures in the Detection of Concealed Information // Journal of Applied Psychology. - 2005. - V. 90. - no. 1. - pp. 147-158.

25. Vorobyeva E. EEG spectral power during the performance of mental tasks and individual profile asymmetry of twins // International Journal of Psychophysiology.-2012.-V.85.-I.3.-P.424. doi:10.1016/j.jpsycho.2012.07.157

26. Vorobyeva E., Ermakov P. Event-related potentials and achievement motivation (research of twins) // International Journal of Psychophysiology. 2012. - V. 85. - I. 3. - P. 421. doi:10.1016/j.ijpsycho.2012.07.149

27. Vorobyeva E. V., Ermakov P. N., Saakyan O. S. The relationships between the achievement motivations and temperaments of psychology students with different lateral organization profiles // Psychology in Russia: State of the Art. - 2015. - V. 8. - I. 1. - pp. 32-42. doi:10.11621/pir.2015.0104 